\title{
Factorial and construct validity of Portuguese version (Brazil) Bergen Facebook Addiction Scale
}

\author{
Validade fatorial e de construto da versão em português \\ (Brasil) da Bergen Facebook Addiction Scale \\ Hugo Rafael de Souza e Silva', Kelsy Catherina Nema Areco², Paulo Bandiera-Paiva², \\ Pauliana Valéria Machado Galvão ${ }^{3}$, Anália Nusya de Medeiros Garcia4, Dartiu Xavier da Silveira ${ }^{5}$
}

\section{Keywords}

Brazil, behavior, addictive, human, psychometrics.

\section{Palavras-chave}

Brasil, comportamento, adição, humano, psicometria.

\begin{abstract}
Objective: To evaluate factorial and construct validity of the Brazilian Portuguese version of the Bergen Facebook Addiction Scale (BFAS-BR). Methods: A sociodemographic questionnaire, the Brazilian Portuguese versions of Online Cognition Scale (OCS-BR) and of BFAS-BR were applied to a sample of Health Undergraduate $(n=356)$. Construct validity evidences were verified through the Confirmatory Factor Analysis. Discriminant validity was examined by correlational analysis between the version of the BFAS-BR and OCS-BR. Results: Proposed factorial model of BFAS did not present a good quality adjustment. So, a model restructuring was necessary from behavioral addiction theoretical views and new model presented satisfactory adjustment quality and construct validity evidence. Correlation between both tested scales was strong ( $\rho=0.707)$ and, therefore, they measure the same construct. Conclusion: The BFAS-BR show adequate factorial and construct validity.
\end{abstract}

\section{RESUMO}

Objetivo: Avaliar a validade fatorial e de construto da versão em português brasileiro da Bergen Facebook Addiction Scale (BFAS-BR). Métodos: Um questionário sociodemográfico e as versões em português brasileiro da Online Cognition Scale (OCS-BR) e da BFAS-BR foram aplicados em uma amostra de universitários de cursos de Saúde $(n=356)$. As evidências da validade de construto foram verificadas por meio da Análise Fatorial Confirmatória. A validade discriminante foi examinada pela análise correlacional das BFAS-BR e OCS-BR. Resultados: O modelo fatorial proposto da BFAS não apresentou bom ajuste. Então, um modelo reestruturado foi necessário a partir das concepções teóricas das adições de comportamento. 0 novo modelo apresentou qualidade de ajustamento satisfatório e evidências de validade de construto. A correlação entre as versões em português de ambas as escalas testadas foi forte $(\rho=0,707)$. Conclusões: A versão em português da Bergen Facebook Addiction Scale apresentou adequada validade de construto.

1 University of Pernambuco (UPE), Medicine College (Serra Talhada Campus, Mental Health and Primary Health Care Discipline, Practice Laboratory, Research and Evaluation in Mental Health), Serra Talhada, PE, Brazil.

3 Oswaldo Cruz Foundation (Fiocruz) Sergio Arouca Public Health National School (ENSP), Department of Epidemiology and Quantitative Methods in Health, Rio de Janeiro, RJ, Brazil.

4 University of Pernambuco (UPE), Biologic Sciences Institute, Recife, PE, Brazil.

5 Federal University of São Paulo (Unifesp), Psychiatry and Medical Psychology Department, São Paulo, SP, Brazil. 


\section{INTRODUCTION}

Facebook is a computer-mediated Social Networking System that has become one of the most popular tools of social communication in the World'. Launched in 2004, it is the most frequently used social network in Brazil2. Studies have shown that some users may make excessive use of the characteristics of Facebook, staying connected long enough to hurt their daily activities ${ }^{3,4}$, thus constituting a new phenomenon called Facebook Addiction.

This phenomenon can be defined as the failure to regulate or moderate use of the Facebook, despite its negative consequences ${ }^{5}$. Some symptoms, similar to other addictions, have been linked to this disorder, such as preference for online interactions, mood change, negative consequences, deficiency in self-regulation ${ }^{6}$, diminished impulse control, withdrawal ${ }^{7}$ and tolerance ${ }^{8}$.

Like any new phenomenon, Facebook Addiction finds many opposition in the academic community and in clinical practice. One of the biggest obstacles to understanding the Facebook Addiction is whether it constitutes a new clinical entity itself, or if it is a part of the spectrum in the Internet Addiction. In the research field, the absence of diagnostic criteria and a validated and widely accepted instrument limit the scope and generalization of the studies?

The lack of a valid instrument can be one of the reasons for the variation in the prevalence. A study with 418 undergraduate students in Lima, Peru, using a modified version of the Diagnostic Questionnaire (DQ) for the screening of Internet Addiction, found a prevalence of $8.6 \%$. Another study conducted on a sample of 355 Filipino undergraduate students found through Facebook Addiction Scale (FAS) a prevalence of $4 \%{ }^{10}$.

To evaluate the Facebook Addiction at least seven psychometric instruments were found: Addictive Tendencies Scale ${ }^{11}$, Facebook Intrusion Questionnaire ${ }^{12}$, Social Networking Website Addiction Scale ${ }^{13}$, Bergen Facebook Addiction Scale ${ }^{14}$, Facebook Dependence Questionnaire 9 , Facebook Addiction Scale ${ }^{15}$ and Addictive Tendencies Towards SNSs ${ }^{16}$.

The Bergen Facebook Addiction Scale (BFAS) has been the most cited instrument in studies on the phenomenon. The BFAS is a self-administered instrument consisting of 18 items grouped into six subscales (salience, withdrawal, tolerance, relapse, mood change and conflicts) ${ }^{14}$.

The BFAS was initially validated in a sample of 423 Norwegian undergraduate students and its construct validity verified by Confirmatory Factor Analysis (CFA) ${ }^{14}$. It was later translated into Portuguese (Brazil) $)^{17}$. Both versions of the instrument presented adequate reliability and stability over time $\mathrm{e}^{14,17}$.

A critique of the CFA performed to validate the BFAS regards the selection of items to compose the factorial structure ${ }^{14}$. The model was composed only by the items with the highest item-total correlation in each of the six sub-scales instrument, that is, only six items entered in the final model.
This fact may mask potential problems on validating the instrument. Therefore, it is argued that to verify the construct validity and quality of the BFAS fit reliably, it is necessary to study all of its 18 items.

Therefore, the aim of this study was to investigate the factorial and construct validity of the Portuguese (Brazil) version of the Bergen Facebook Addiction Scale (BFAS-BR).

\section{METHODS}

The sample was constituted of 382 undergraduate students, regularly enrolled from the first to the last year of health courses (Medicine, Nursing, Dentistry, Biological Sciences and Physical Education) from the Institute of Biological Sciences, University of Pernambuco, 23 subjects were excluded from the sample due to inadequate completion of the data collection instruments and three for not having Facebook profile (Table 1). At the end, a sample of 356 individuals was considered, being 271 (75.4\%) women, with a mean age of 19.47 years (Standard Deviation $=2.32$ years) $($ Table 1$)$.

Table 1. Characteristic sociodemographic and usage habits of the internet

\begin{tabular}{|c|c|c|}
\hline Variable & N & $\%$ \\
\hline \multicolumn{3}{|l|}{ Gender } \\
\hline Female & 88 & 24.5 \\
\hline Male & 271 & 75.5 \\
\hline \multicolumn{3}{|l|}{ Study time } \\
\hline Full diurnal & 356 & 99.2 \\
\hline Morning diurnal & 2 & 0.6 \\
\hline Afternoon diurnal & 1 & 0.3 \\
\hline \multicolumn{3}{|l|}{ Skin color } \\
\hline White & 167 & 46.5 \\
\hline Black & 22 & 6.1 \\
\hline Mulato & 163 & 45.4 \\
\hline Yellow & 4 & 1.1 \\
\hline Indigenous & 3 & 0.8 \\
\hline \multicolumn{3}{|l|}{ Marital state } \\
\hline Single & 343 & 95.5 \\
\hline Married & 5 & 1.4 \\
\hline Widow & 3 & 0.8 \\
\hline Divorced & 1 & 0.3 \\
\hline Stable union & 7 & 1.9 \\
\hline \multicolumn{3}{|l|}{ Escolarity } \\
\hline Incomplete high school & 1 & 0.3 \\
\hline Complete high school & 4 & 1.1 \\
\hline Incomplete higher education & 350 & 97.5 \\
\hline Complete higher education & 2 & 0.6 \\
\hline Post-graduation & 2 & 0.6 \\
\hline
\end{tabular}




\begin{tabular}{|c|c|c|}
\hline Variable & N & $\%$ \\
\hline \multicolumn{3}{|l|}{ Family income } \\
\hline Up to 3 minimum salaries (MS) & 105 & 29.2 \\
\hline Between 3 to $10 \mathrm{MS}$ & 155 & 43.2 \\
\hline Between 10 to 20 MS & 53 & 14.8 \\
\hline Between 20 to 30 MS & 30 & 8.4 \\
\hline More $30 \mathrm{MS}$ & 16 & 4.5 \\
\hline \multicolumn{3}{|l|}{ Access local } \\
\hline Home & 345 & 96.1 \\
\hline Work & 45 & 12.5 \\
\hline Educational institution & 242 & 67.4 \\
\hline \multicolumn{3}{|l|}{ Weekly connection time } \\
\hline Until 10 hours & 114 & 31.8 \\
\hline Between 10 and 20 hours & 138 & 38.4 \\
\hline Between 20 and 40 hours & 44 & 12.3 \\
\hline More 40 hours & 29 & 8 \\
\hline \multicolumn{3}{|c|}{ Do you use internet to maintain personal relationships? } \\
\hline Yes & 153 & 42.6 \\
\hline No & 206 & 57.4 \\
\hline \multicolumn{3}{|c|}{ Do you use the internet to pass the time? } \\
\hline Yes & 221 & 61.6 \\
\hline No & 138 & 38.4 \\
\hline \multicolumn{3}{|c|}{ Do you use the internet to get information? } \\
\hline Yes & 335 & 93.3 \\
\hline No & 24 & 6.7 \\
\hline \multicolumn{3}{|c|}{ Do you use the internet for convenience? } \\
\hline Yes & 240 & 66.9 \\
\hline No & 119 & 33.1 \\
\hline \multicolumn{3}{|c|}{ Do you use the internet for entertainment? } \\
\hline Yes & 262 & 73 \\
\hline No & 97 & 27 \\
\hline
\end{tabular}

\section{Instruments}

To collect data, three instruments were used: a questionnaire of socio demographic characteristics and internet usage habits; the versions in Portuguese (Brazil) of the Online Cognition Scale (OCS-BR) and the Bergen Facebook Addiction Test (BFAS-BR).

The questionnaire consisted of questions about sex, age, graduation course, income, marital status, internet access, weekly usage time, motivations in internet usage, applications/tools used and negative impacts from use of the internet in everyday life.

The used OCS version was translated into Portuguese (Brazil) in previous study ${ }^{18}$. It consists of a self-administered instrument composed of 36 items and answered on a Likert scale, with a score of one (completely disagree) to seven points (totally agree). The score ranges from 36 to 252 points and is directly related to the level of Problematic Internet Use (PIU) ${ }^{19}$.

The BFAS was developed by Andreassen et al. ${ }^{14}$ which aim is to measure the Facebook Addiction. It consists of a selfadministered instrument, answered in a Likert scale ranging from 1 (very rarely) to 5 (very often). The score ranges from 18 to 90 points. The items of the instrument are grouped into six dimensions of the addictions proposed by Griffiths ${ }^{20}$. The BFAS was translated into Portuguese (Brazil) in study of Silva et al. ${ }^{17}$

\section{Procedures}

Data collection was during the class period between the months April to June 2013 in accordance with the authorization provided by the institution and its professors. The instruments application occurred after a brief orientation to fill and sign the Informed Consent (IC). Then the instruments were distributed and applied collectively. Moreover, the time for its completion was timed, which on average took 15 minutes.

\section{Data analysis}

Analysis of construct validity of BFAS-BR followed the guideline suggested by Hair et al. ${ }^{21}$ and Marôco ${ }^{22}$ for confirmatory factor analysis (CFA).

The CFA is an effective method for construct validity through factorial and convergent validities. Construct validity is understood by the degree to which a set of manifest variables really reflects the theoretical latent construct which is intended to measure ${ }^{21}$. The CFA is the most suitable method to investigate the construct validity through factorial and convergent validities.

Prior to its execution, the presence of multivariate outliers and normality assumption of univariate and multivariate were verified. These were analyzed by the ratio Distance Square Mahalanobis $\left(D^{2}\right)$ and degrees of freedom (df). The outliers were the individuals who had the ratio $\geq 3^{21}$. The univariate and multivariate normality were carried through the asymmetry coefficients ( $\mathrm{Sk}$ ) and kurtosis (Ku) and considered violation of the assumption of normality indicators $\mid$ Sk $\mid \geq$ 3 and $|\mathrm{Ku}| \geq 10^{22,23}$. It was used the maximum likelihood method to estimate the fitting quality of the model.

To test the fitting of the model, quality measures were used. These to be considered acceptable must present the following values: chi-square test ( $\left.x^{2}\right) / d f:$ 1 ; 2]; Goodness of Fit Index (GFI): $\geq 0.95$; Comparative Fit Index (CFI): $\geq 0.95$; Root Mean Square Error of Approximation (RMSEA): $\leq 0.07^{21,22 ;}$ Modified Expected Cross-Validation Index (MECVI): In order to compare, the model with the lowest MECVI value is the best and most stable model in the population ${ }^{22}$.

Factorial validity is achieved when the specification of the items of a certain latent construct has satisfactory fit quality. This type of validity is checked using the standardized factor 
loadings $\left(\lambda^{2}\right)$. There will be factorial validity when all the manifest variables present $\lambda^{2} \geq 0.25^{22}$.

Convergent validity is the degree to which the manifest variables converge or share a high proportion of common variance with the latent construct ${ }^{21}$. For a model to present convergent validity of the factor loadings $(\lambda)$ must be $\geq 0.5$ and significant $(p<0.05)^{20}$, Average Variance Extracted (AVE) $\geq 0.5$, Construct reliability $(C R) \geq 0.724$.

Moreover, the correlation between the BFAS-BR and the OCS-BR was seen to verify the discriminant validity between the constructs: Addiction to Facebook and the Problematic Internet Use.

Descriptive statistics, bivariate analysis and reliability were performed using statistical software SPSS v. 20 and the CFA by means of SPSS AMOS v.20.

\section{RESULTS}

To reach the objective of this study, the CFA of the BFAS-BR was carried out. Violations to the assumptions of uni- and multivariate normality and the presence of multivariate outliers weren't verified. The choice of manifest variables to compose the proposed model in the CFA followed the same procedure performed by Andreassen et al. ${ }^{14}$

The items with the highest item total correlation in each of the six dimensions of the instrument identified in Silva et al. ${ }^{17}$ were brought into the proposed model (Table 2).
Graphically the factor model of BFAS-BR prepared by Andreassen et al..$^{14}$ was represented according to Figure 1. This figure demonstrates the specification of the model, being the formal design of the theoretical model being tested in the study. In the proposed model by Andreassen et al..$^{14}$ only the item with the highest item-total correlation of each of the six dimensions of the instrument reflect the theoretical reference for the Facebook Addition.

According to the results of the CFA the above model revealed the following quality indicators: $x^{2} / d f=1.57(p=$ 0.118), $\mathrm{GFI}=0.98, \mathrm{CFI}=0.98, \mathrm{RMSEA}=0.40$ e $\mathrm{MECVI}=0.107$. The $\lambda$ ranged between 0.47 and 0.71 , being the lowest for the item 7. All $\lambda$ were statistically significant $(P<0.001)$. The CR was of 0.77 and the AVE of 0.37. The manifest variables presented explained variance (EV) ranging from 0.22 to 0.50 , being the lowest related to item 7 and the highest to item 5 .

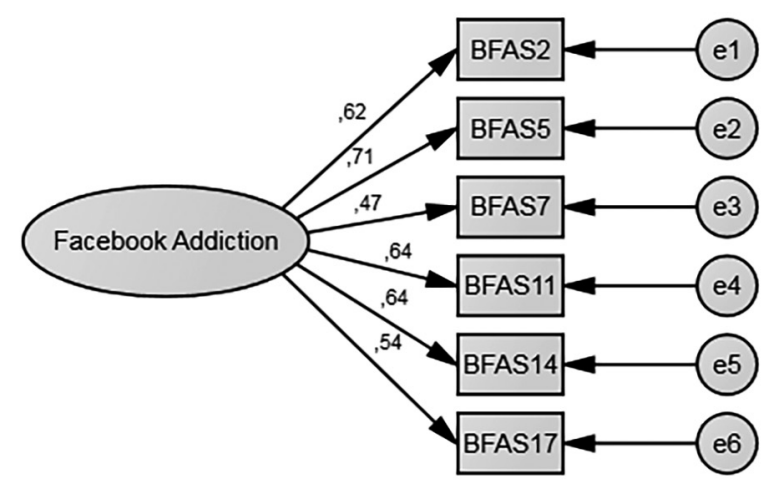

Figure 1. Fatorial Model proposed by Andreassen et al.14.

Table 2. Item-Total Correlation of BFAS-BR

\begin{tabular}{|c|c|c|}
\hline Dimension & Items & Item-Total Correlation \\
\hline \multirow[t]{3}{*}{ Salience } & 1. Spent a lot of time thinking about Facebook or planned use of Facebook? & 0.69 \\
\hline & 2. Thought about how you could free more time to spend on Facebook? & $0.91^{*}$ \\
\hline & 3. Thought a lot about what has happened on Facebook recently? & 0.64 \\
\hline \multirow[t]{3}{*}{ Tolerance } & 4. Spent more time on Facebook than initially intended? & 0.52 \\
\hline & 5. Felt an urge to use Facebook more and more? & $0.71^{*}$ \\
\hline & 6. Felt that you had to use Facebook more and more in order to get the same pleasure from it? & 0.60 \\
\hline \multirow[t]{3}{*}{ Mood modification } & 7. Used Facebook in order to forget about personal problems? & $0.74^{*}$ \\
\hline & 8. Used Facebook to reduce feelings of guilt, anxiety, helplessness, and depression? & 0.70 \\
\hline & 9. Used Facebook in order to reduce restlessness? & 0.68 \\
\hline \multirow[t]{3}{*}{ Relapse } & 10. Experienced that others have told you to reduce your use of Facebook but not listened to them? & 0.62 \\
\hline & 11. Tried to cut down on the use of Facebook without success? & $0.83^{*}$ \\
\hline & 12. Decided to use Facebook less frequently, but not managed to do so? & 0.79 \\
\hline \multirow[t]{3}{*}{ Withdrawal } & 13. Become restless or troubled if you have been prohibited from using Facebook? & 0.73 \\
\hline & 14. Become irritable if you have been prohibited from using Facebook? & $0.81^{*}$ \\
\hline & 15. Felt bad if you, for different reasons, could not log on to Facebook for some time? & 0.61 \\
\hline \multirow[t]{3}{*}{ Conflict } & 16. Used Facebook so much that it has had a negative impact on your job/studies? & 0.47 \\
\hline & 17. Given less priority to hobbies, leisure activities, and exercise because of Facebook? & $0.64^{*}$ \\
\hline & 18. Ignored your partner, family members, or friends because of Facebook? & 0.59 \\
\hline
\end{tabular}

* Items with the highest item-total correlation. 
The $\lambda$ and the EV from item 7 inferior to 0.5 and 0.25 , respectively, and the AVE of the instrument inferior than 0.5 weakens the evidence of convergent and factorial validity of the model above. It is also highlighted that inadequate RMSEA jeopardizes the quality of model fit. Therefore, the results for the CFA of the BFAS-BR following the model proposed by Andreassen et al..$^{14}$ indicates the absence of factor and convergent validity, that is, undertakes the construct validity. Given the above, it is proposed a new factor model for BFAS$B R$ considering the six core dimensions of the addictions proposed by Griffith ${ }^{20}$ that serve as basis in the elaboration of the BFAS.

For the new model, the 18 items of the BFAS were grouped in the form of parceling in their respective dimensions $s^{14,17}$. The factor structure of the new factor model was depicted as follows (Figure 2).

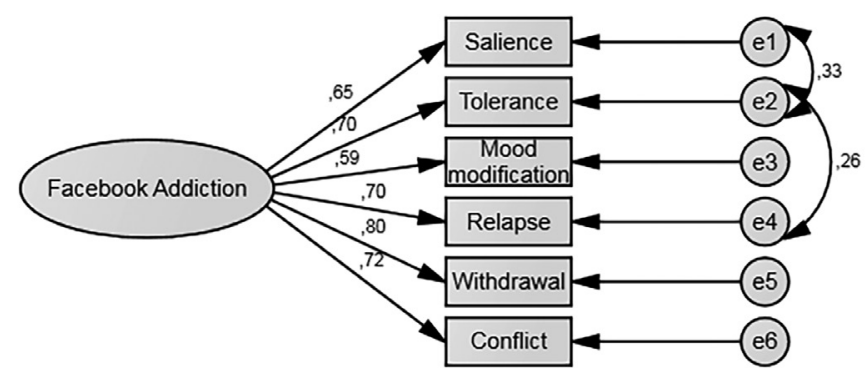

Figure 2. Fatorial structure for BFAS proposed by this study.

The model proposed in this study expands the specification of the factorial model proposed by Andreassen et $a . .^{14}$, considering the parceling of all items of the six dimensions. In this way, it is possible to statistically test which of the theoretical models proposed for the Facebook Addiction to exhibit a better fit.

The CFA for the new model of the BFAS-BR presented the following quality indicators: $x^{2} / d f=1.13(p=0.341), G F I=$ 0.99, $\mathrm{CFI}=0.99, \mathrm{RMSEA}=0.01$ and $\mathrm{MECVI}=0.103$. The $\lambda$ vary between 0.59 and 0.80 , being all $\lambda$ statistically significant $(P<$ $0.001)$. The CR was of 0.84 and the AVE of 0.49 . The manifest variables presented EV varying between 0.34 and 0.64 . The $\mathrm{EV}$ of each variable was: salience $\mathrm{EV}=0.42$, tolerance $\mathrm{EV}$
$=0.49$, mood modification $\mathrm{EV}=0.34$, Relapse $\mathrm{EV}=0.49$, withdrawal $\mathrm{EV}=0.64$ and Conflicts $\mathrm{EV}=0.51$. The errors $\mathrm{E} 1$, $E 2, E 3$ and E4 were correlated with the changes from the indices (above 11; $\mathrm{P}<0.001$ ) produced by SPSS Amos and based on theoretical considerations. The model presents fitting of quality indicators covering a very good adaptation of the factor structure of BFAS-BR, showing clear evidence of factorial and convergent validity, i.e., construct validity.

In comparison, the new model had a significantly higher fit quality to the original mode ${ }^{14}$ in the studies sample, this can be evidenced by the lower MECVI (0.103 vs. 0.107) and the unequivocal adequacy of the fit quality indicator RMSEA. However, it is emphasized that the AVE of the new model was slightly less than 0.5 , but the other convergent validity indicators were appropriate. Therefore, it is concluded that there was no impairment of convergent validity of the instrument.

Table 3 presents the correlation coefficients of Spearman ( $\rho)$ among the six BFAS-BR subscales. Correlations ranged between 0.269 and 0.497 , all of which were statistically significant $(p<0.001)$. The correlation between the studied version of BFAS-BR and OCS-BR was $\rho=0.707$.

\section{DISCUSSION}

The aim of this study was to investigate the factorial and construct validity of the Portuguese version of the Bergen Facebook Addiction Scale (BFAS-BR) by confirmatory factor analysis (CFA). The adequacy of the data to the factor model proposed by Andreassen et al. ${ }^{14}$ was tested. However, the CFA performed for this model did not find evidence of factorial and convergent validity, in fact, this affected the construct validity for the instrument. Given this scenario and strongly considering the theory that underlies the BFAS-BR, a new factor model to the instrument was elaborated, which provided sufficient evidence for the construct validity.

The factor structure developed by Andreassen et al. ${ }^{14}$ for the BFAS considers only the items with the highest overall correlation of the items in each of the subscales. This procedure contributes for a better model fitting, since only those items that already have a strong correlation between

Table 3. Correlation between the BFAS-BR subscales

\begin{tabular}{|c|c|c|c|c|c|c|c|}
\hline & & Salience & Tolerance & Mood modification & Relapse & Withdrawal & Conflict \\
\hline \multirow{6}{*}{$\begin{array}{l}\text { Kendall's Tau } \\
\text { Coefficient }\end{array}$} & Salience & 1.000 & $0.484^{* *}$ & $0.337^{* *}$ & $0.304^{* *}$ & $0.424^{* *}$ & $0.411^{* *}$ \\
\hline & Tolerance & $0.484^{* *}$ & 1.000 & $0.329^{* *}$ & $0.497^{* *}$ & $0.448^{* *}$ & $0.398^{* *}$ \\
\hline & Mood modification & $0.337^{* *}$ & $0.329^{* *}$ & 1.000 & $0.269^{* *}$ & $0.366^{* *}$ & $0.299^{* *}$ \\
\hline & Relapse & $0.304^{* *}$ & $0.497^{* *}$ & $0.269^{* *}$ & 1.000 & $0.437^{* *}$ & $0.394^{* *}$ \\
\hline & Withdrawal & $0.424^{* *}$ & $0.448^{* *}$ & $0.366^{* *}$ & $0.437^{* *}$ & 1.000 & $0.474^{* *}$ \\
\hline & Conflict & $0.411^{* * *}$ & $0.398^{* *}$ & $0.299^{* *}$ & $0.394^{* *}$ & $0.474^{* *}$ & 1.000 \\
\hline
\end{tabular}

\footnotetext{
** Significant correlation in 0.01 (bicaudal) level.
} 
them, and the construct are taken into the model. Another fact to be considered for a possible better fit is the decreasing of the manifest variables, because the simpler the model, the better the fit quality ${ }^{21}$. However, these procedures were not sufficient to ensure the quality of the fit BFAS in the studied population.

The fit of the population data in the study model developed by Andreassen et al. ${ }^{14}$ can be considered unbearable. The RMSEA indicator greater than 0.10 are considered unacceptable ${ }^{21-23}$.

Item 7 presented $\lambda^{2}$ equal to 0.22 . Factorial validity is checked when all model manifest variables show $\lambda^{2} \geq 0.25^{22}$. This represents how much variation of an item is explained in the construct ${ }^{21}$. In this case, only $22 \%$ of the item is explained in the construct, the remaining $78 \%$ corresponds to the error variance. This fact would elect the item to be deleted. In the original study, the item 7 was also the one with lowest explained variance $(E V=0.34)$.

The factor model proposed by BFAS, Andreassen et al. ${ }^{14}$ in the sample studied presented AVE $=0.37$. The AVE is an indicator of convergent validity, or when the behavior of the set of items is explained by the construct to which they are related $^{22}$. In this model, the Facebook Addiction construct explained $37 \%$ of explained variance of the items, in other words, on average, $63 \%$ more errors remain in the items than the explained variance. A possible explanation for this is the number of items to cover the phenomenon. The BFAS was designed with 18 items, however in the model only one item of each sub-scale entered the model, six in total. Therefore, this amount of items ${ }^{7}$ is insufficient to perceive the phenomenon Facebook Addiction. In addition, only one item of each sub scale is also insufficient to represent the whole dimension.

The absence of factorial and convergent validity in the sample studied for BFAS model developed by Andreassen et al. ${ }^{14}$ made us put forward an alternative model, considering all the 18 items of BFAS and the theoretical model behind the instrument. The 18 items were grouped into six portions, corresponding to the six core dimensions of addictions (salience, tolerance, conflict, mood modifications, withdrawal and relapse) ${ }^{21}$, this enhances the representation of the items in the instrument.

The new model presented satisfactory quality fit indicators, convergent validity, and factorial validity, i.e., construct validity evidence, comparing to the model developed by Andreassen et al.14. Also, in this study, it is highlighted that the model proposed presents a better fit in the studied sample than the original model, given the lower MECVI. We believe that the psychometric qualities of the new model portrayed here in this study are better than that presented by Andreassen et al. ${ }^{14}$ due to the extension of the model specification. Our model aggregates all items of the instrument, increasing the representation of the items for the Facebook Addiction construct, by simplifying the model of Andreassen et al. ${ }^{14}$ create a strategy to improve fit qualities, since models with fewer variables have the potential for better fit ${ }^{22}$.

The errors of the manifest variables salience, tolerance and relapse were correlated as suggested by the statistical software through the modification of the indices. When manifest variables belonging to the same construct present errors correlated to each other, this can mean similarities in the formulation or content items. Another aspect is that the correlation between errors may indicate the existence of constructs of higher hierarchical order that were not considered in the mode ${ }^{22}$.

The variance explained by the manifest variables in the alternative model proposed here varied between 34\%-64\%, all fit. However, even with proper value, we highlight that the lowest value was found to the variable mood modification, similar to that found in the original validation study of the BFAS $^{14}$. The study developed by Widyanto et al. ${ }^{25}$ verified the factorial structure of two psychometric tools for tracking internet addiction the Internet Addcition Test (IAT) e o InternetRelated Problem Scale (IRPS), for the dimension of mood modification of the first instrument showed EV of $5.61 \%$ and the second of $7.33 \%$. The suitable EV is when $\geq 25 \%{ }^{21}$. The low variance explained the mood modification on the scales for technological addictions need to be further studied in order to establish the maintenance or not of this dimension in the instruments.

The BFAS-BR subscales showed correlation values between them ranging between 0.269 and 0.497 , indicating that there is no overlapping between the subscales, in psychometric terms, they seem to measure different dimensions. This means evidence of discriminant validity among the subscales.

The BFAS-BR showed correlation of 0.707 with the OCSBR. This type of correlation between a new instrument and another test, such as these, proves that they measure approximately the same construct ${ }^{26}$, in other words, the construct Addiction to Facebook and Problematic Use of the Internet don't seem to be quite independent of each other.

Although the results of our study are satisfactory some limitations need to be considered. A convenience sample limits the generalization of the results to the public. Another fact is that both, this study and Andreassen et al.'s study ${ }^{14}$ were carried out on samples of predominantly female college students and, so the use of BFAS in other populations and/or age groups deserves caution. Studies with other populations should be performed to ensure a safe application in clinical and research settings.

Other aspects related to BFAS need further studies, such as: 1. establishing a cutoff point; 2 . checking for a possible 
factor in the second order factor structure suggested; 3 . examining discriminating validity among Addiction to Facebook and Problematic Use Internet; 4. studying the maintenance or not of the dimension mood modification in the screening tools of technological addictions, among them Addiction to Facebook.

\section{CONCLUSION}

The BFAS-BR presented sufficient evidence of construct validity for the factor model that considered the 18 items of the instrument, suggesting that the six dimensions of addictions are gathered to measure addiction to Facebook through the Bergen Facebook Addiction Scale.

Psychometric qualities of the instrument verified in this study are sufficient for the cautious use of the same in the clinical and epidemiological scenarios, being necessary to broaden the understanding of the phenomenon Facebook Addiction, mainly in the Brazilian population. Validation of the Portuguese version (Brazil) is a first step in this direction. Therefore, other studies with other populations should be performed, since what supports the construct validity of an instrument is the constant updating of the set of evidences found in several studies.

\section{INDIVIDUAL CONTRIBUTIONS}

Hugo Rafael de Souza e Silva - Contributed to the conception, design, analysis and interpretation of the data, writing of the article and final approval of the version to be published.

Kelsy Catherina Nema Areco - Contributed to the analysis and interpretation of the data, relevant critical review of the intellectual content and final approval of the version to be published.

Paulo Bandiera-Paiva - Contributed to the analysis and interpretation of the data, relevant critical review of the intellectual content and final approval of the version to be published.

Pauliana Valéria Machado Galvão - Contributed to the analysis and interpretation of the data, relevant critical review of the intellectual content and final approval of the version to be published.

Analia Nusya de Medeiros Garcia - Collaborated in the conception and design, relevant critical revision of the intellectual content and final approval of the version to be published.

Dartiu Xavier da Silveira - Contributes to the conception, design, analysis and interpretation of the data, writing of the article and final approval of the version to be published.

\section{CONFLICTS OF INTEREST}

The authors Hugo Rafael de Souza e Silva, Dartiu Xavier da Silveira, Kelsy Catherina Nema Areco, Paulo Bandiera-Paiva and Anália Nusya de Medeiros Garcia declare that there is no conflict of interest in relation to this article. The author Pauliana Valéria Machado Galvão declares receiving doctoral scholarship from the Coordination of Improvement of Higher Education Personnel (Capes/Ministry of Education), with a doctorate in Epidemiology of Public Health, Sérgio Arouca National School of Public Health, Oswaldo Cruz Foundation.

\section{REFERENCES}

1. Ross C, Orr ES, Sisic M, Arseneault JM, Simmering MG, Orr RR. Personality and motivations associated with Facebook use. Comput Hum Behav. 2009;25(2):578-86.

2. Reis PCSSC, Leite ÂMT, Amorim SMM, Souto TS. A solidão em utilizadores portugueses do Facebook. Psicol Soc. 2016;28(2):237-46

3. Griffiths MD. Facebook addiction: concerns, criticism, and recommendations--a response to Andreassen and colleagues. Psychol Rep. 2012;110(2):518-20.

4. Kuss DJ, Griffiths MD. Online Social Networking and Addiction - a review of the psychological literature. Int J Environ Res Public Health. 2011;8(9):3528-52.

5. La Rose R, Mastro D, Eastin M. Understanding Internet usage: a social-cognitive approach to uses and gratifications. J Soc Sci Comput Rev. 2001;19(4):395-413.

6. Lee Z, Cheung C, Thadani D, editors. An investigation into the problematic use Facebook In: Proceedings of the 45th International Conference on System Science. Hawaii; 2012.

7. Balakrishnan V, Shamim A. Malaysian Facebookers: motives and addictive behaviours unraveled. Comput Hum Behav. 2013;29:1342-9.

8. Zaremohzzabieh Z, Samah B, Omar S, Bolong J, Kamarudin N. Addictive Facebook use among university students. Asian Soc Sci. 2014;10(6):107-16.

9. Wolniczak I, Cáceres-DelAguila JA, Palma-Ardiles G, Arroyo KJ, Solís-Visscher R, ParedesYauri $S$, et al. Association between Facebook dependence and poor sleep quality: a study in a sample of undergraduate students in Peru. PLoS One. 2013:8(3):e59087.

10. Marcial DE. Are you a Facebook addict? Measuring Facebook addiction in the Philippine University. Int Proc Econ Dev Res. 2013;66:12-5.

11. Wilson K, Fornasier S, White KM. Psychological predictors of young adults' use of social networking sites. Cyberpsychol Behav Soc Netw. 2010;13(2):173-7.

12. Elphinston RA, Noller P. Time to face it! Facebook intrusion and the implications for romantic jealousy and relationship satisfaction. Cyberpsychol Behav Soc Netw. 2011;14(11): $631-5$.

13. Turel 0 , Serenko $A$. The benefits and dangers of enjoyment with social networking websites. Eur J Inf Syst. 2012;21(5):512-28.

14. Andreassen CS, Torsheim T, Brunborg GS, Pallesen S. Development of a Facebook Addiction Scale. Psychol Rep. 2012;110(2):501-17.

15. Koc M, Gulyagci S. Facebook addiction among Turkish college students: the role of psychological health, demographic, and usage characteristics. Cyberpsychol Behav Soc Netw. 2013;16(4):279-84

16. Wu AM, Cheung VI, Ku L, Hung EP. Psychological risk factors of addiction to social networking sites among Chinese smartphone users. J Behav Addict. 2013;2(3):160-6.

17. Silva HRS, Areco KCN, Bandiera-Paiva P, Galvão PVM, Garcia ANM, Silveira DX. Equivalência semântica e confiabilidade da versão em português da Bergen Facebook Addiction Scale. J Bras Psiquiatr. 2015;64(1):17-23.

18. Silva HRS, Areco KCN, Bandiera-Paiva P, Galvão PVM, Garcia ANM, Silveira DX. Avaliação da equivalência semântica da versão em português (Brasil) da Online Cognition Scale. Cad Saúde Pública. 2014;30(6):1327-34.

19. Davis RA, Flett $G L$, Besser A. Validation of a new scale for measuring problematic internet use: implications for pre-employment screening. Cyberpsychol Behav. 2002;5(4):331-45. 
20. Griffiths M. A "components" model of addiction within a biopsychosocial framework. J Subst Use. 2005;10(4):191-7.

21. Hair JF, Black WC, Babin BJ, Anderson RE, Tathan RL. Multivariate data analysis. 6th ed. New York: John Wiley; 2009.

22. Marôco J. Análise de equações estruturais: fundamentos teóricos, software \& aplicações. 1a ed. Lisboa: ReportNumber; 2010.

23. Kline RB. Principles and practice of structural equation modeling. 2nd ed. New York: Guilford publications; 2015.
24. Fornell C, Larcker DF. Evaluating structural equation models with unobservable variables and measurement error. J Mark Res. 1981;18(1):39-50.

25. Widyanto L, Griffiths MD, Brunsden V. A psychometric comparison of the Internet Addiction Test, the Internet-Related Problem Scale, and self-diagnosis. Cyberpsychol Behav Soc Netw. 2011;14(3):141-9.

26. Mackenzie SB, Podsakoff PM, Jarvis CB. The problem of measurement model misspecification in behavioral and organizational research and some recommended solutions. J Appl Psychol. 2005;90(4):710-30. 